\title{
Sarcoidosis with severe renal impairment in a young patient
}

\author{
Veronika Meshechko* \\ Nephrology, Internal medicine, Latvia
}

\begin{abstract}
The patient was admitted to the hospital with complaints about headache, high blood pressure with frequent hypertensive crises. Laboratory tests showed renal insufficiency with serum creatinine of $295 \mathrm{mcmol} / \mathrm{L}$ (GFR MDRD $23 \mathrm{ml} / \mathrm{min}$ ) and severe hypercalcemia $3.9 \mathrm{mmol} / \mathrm{L}$. Patient has known hebephrenic schizophrenia from adolescence and is on a regular treatment. To identify the cause of hypercalcemia and renal insufficiency different investigations were performed including laboratory tests, chest and abdominal computed tomography scans. Performed investigations suggested diagnosis of sarcoidosis that was confirmed by lung biopsy, where typical epithelioid granulomas were found. Kidney biopsy was also performed to clarify cause of kidney insufficiency. Biopsy revealed mild chronic interstitial inflammation with focal calcification. Patient started prednisolone, and his serum creatinine and calcium decreased. He was discharged from the hospital in a good general condition with recommendations to continue treatment with steroids and be under the supervision of pneumonologist and nephrologist.
\end{abstract}

\section{Learning points}

- Kidney involvement due to sarcoidosis can be observed, although it is rare.

- Treatment with steroids can improve kidney function and decrease serum calcium level.

\section{Introduction}

Sarcoidosis is an inflammatory disease that affects multiple organ systems but mostly lungs and chest lymph nodes where abnormal nodules called granulomas can be found [2]. The incidence is $16.5 / 100.000$ in men and 19/100.000 in women [3]. Kidney involvement in sarcoidosis is rare, and mostly have been reported as single case reports. [1]. The incidence of renal involvement in sarcoidosis ranges from $3-23 \%$.

\section{Case report}

A 32-year-old Caucasian male, non-smoker, married, has two children, was admitted to the Nephrology department because of the increased serum creatinine level. One month ago he was admitted to the Cardiology department because of hypertensive crisis. The investigations showed elevated serum creatinine level but were thought to be associated with therapy with non-steroidal anti-inflammatory drugs because of chronic headache.

At the time of admission the main complaints were headache, red, teary eyes, periodic blurred vision, elevated blood pressure, $20 \mathrm{~kg}$ weight loss during last six months and pain in the lower jaw.

The patient had previous history of elevated blood pressure for approximately one year and used prescribed medications: bisoprolol $5 \mathrm{mg}$, amlodipin $10 \mathrm{mg}$, moxonidin $0.4 \mathrm{mg}$. His blood pressure was mostly $140 / 90 \mathrm{mmHg}$. Also, the patient since age of 16 had hebephrenic schizophrenia, attended psychiatrist on regular basis and was taking bromazepam, quetiapinum and flupentixolum.
On admission to the Nephrology department laboratory findings showed anemia with hemoglobin of $11.5 \mathrm{~g} / \mathrm{L}$ (normal range: 12 to 16 ), serum creatinine $320 \mathrm{mcmol} / \mathrm{L}$ (GFR MDRD $20.9 \mathrm{ml} / \mathrm{min}$ ) and urea $13 \mathrm{mmol} / \mathrm{L}$ (normal range: 3.2 to 8.2 ). There was hypercalcemia of 3.9 $\mathrm{mmol} / \mathrm{L}$ (normal range: 2.0 to 2.6 ), with elevated ionized calcium of 1.8 $\mathrm{mmol} / \mathrm{L}$ (normal range: 1.1 to 1.2 ). 24 -hour urine calcium excretion showed hypercalciuria: $27.7 \mathrm{mmol} / \mathrm{L}$ ( 2.5 to 7.5 ). The inflammatory markers as C-reactive protein were normal. Serological tests showed no evidence of infection. Angiotensin-converting enzyme level in the blood was elevated: $110 \mathrm{U} / \mathrm{L}(<70 \mathrm{U} / \mathrm{L})$, which is typically elevated in case of sarcoidosis. Parathyroid hormone was normal: $44.3 \mathrm{pg} / \mathrm{ml}$ (normal range: 14 to 72 ). There was mild proteinuria and microscopic hematuria.

Chest computed tomography scan showed bilaterally enlarged hilar, mediastinal, cervical and axillar lymph nodes (Figure 1).

The bronchoscopy with lung biopsy was performed. Epithelioid granulomas with multinucleated giant cells and cytoplasmic mineralization, and fibrosis of surrounding tissue were found, which proved the diagnosis of sarcoidosis (Figure 2).

The kidney biopsy sample contained renal cortex with 28 glomeruli, 3 of them were globally sclerosed. Few glomeruli revealed slight mesangioproliferative changes. The interstitium was focally expanded with mononuclear cell infiltrates occupying approximately $20 \%$ of a cortical area and few calcified deposits in the interstitium that were surrounded by small groups of giant cells. Calcified deposits were positive in Van Kossa histochemical staining. Mentioned findings can be interpreted as mild chronic interstitial inflammation with focal calcification (Figure 3).

Correspondence to: Veronika Meshechko, Nephrology, Internal medicine, Latvia, E-mail: 7veronika@inbox.lv

Key words: Sarcoidosis, kidney insufficiency, hypercalcemia

Received: November 29, 2017; Accepted: January 03, 2018; Published: January 06 , 2018 


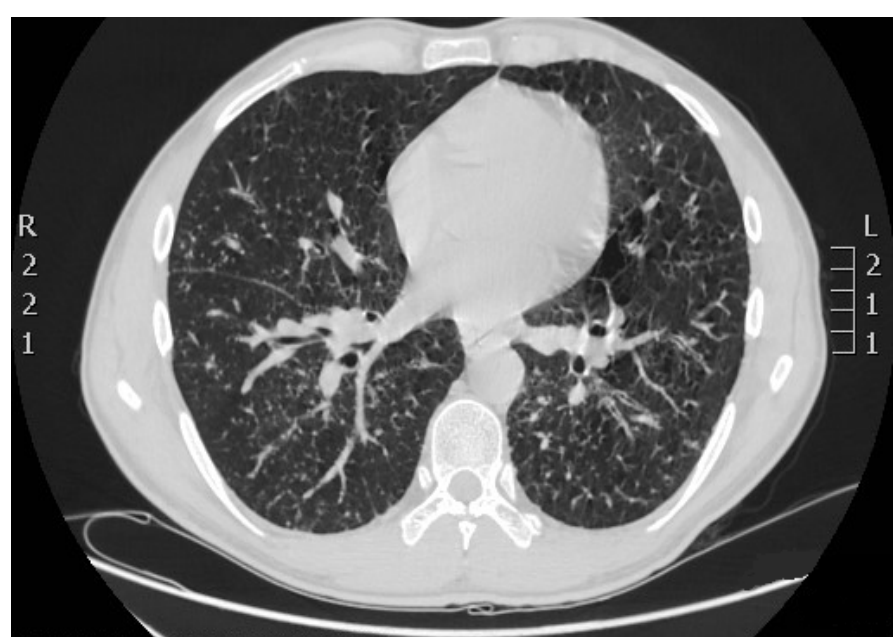

Figure 1. Chest computed tomography scan.

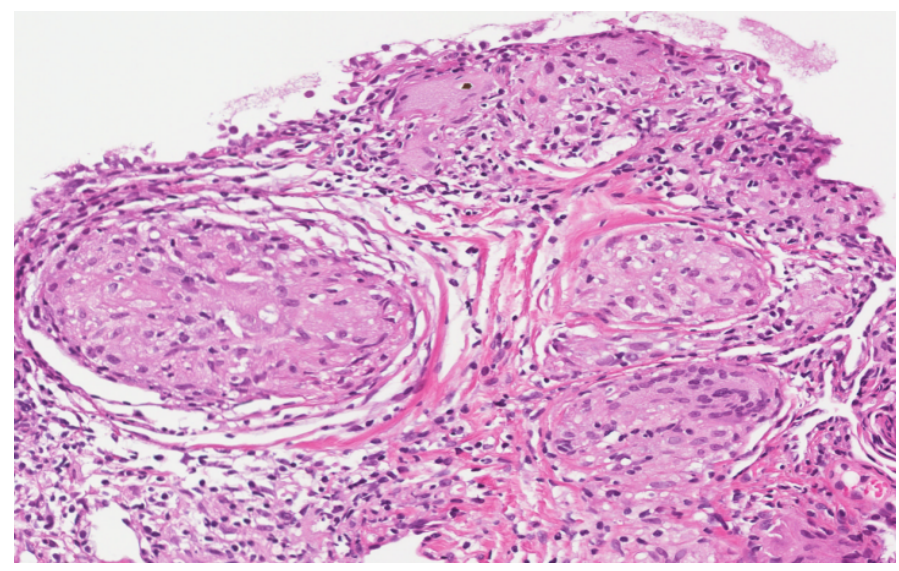

Figure 2. The lung biopsy (HE staining).

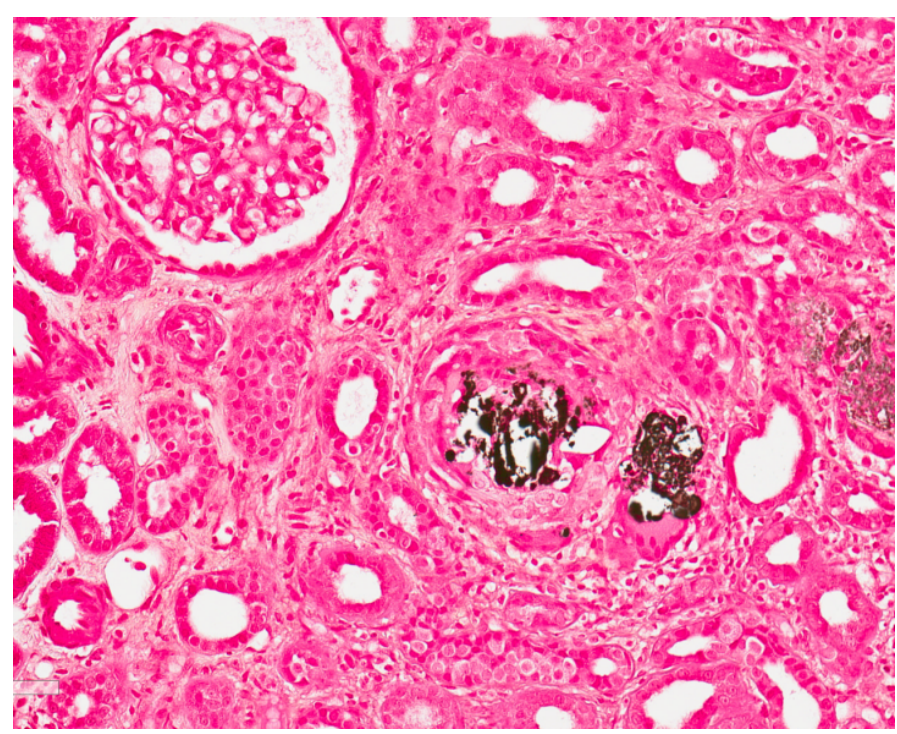

Figure 3. The kidney biopsy (Van Kossa staining).

Patient had additional investigations after the diagnosis of sarcoidosis was established. Eye examination showed no pathology. An echocardiogram and electrocardiogram were unremarkable. Brain magnetic resonance didn't show any abnormal findings.
The standard treatment of sarcoidosis is based on corticosteroids. The treatment with $60 \mathrm{mg}$ of prednisolone was started. After that improvement of laboratory findings was observed: serum creatinine decreased from $320 \mathrm{mcmol} / \mathrm{L}$ to $157 \mathrm{mcmol} / \mathrm{L}$ (GFR MDRD $47.5 \mathrm{ml} /$ $\mathrm{min}$ ) and serum calcium normalized to $2.5 \mathrm{mmol} / \mathrm{L}$. Complaints about headache, red, teary eyes and pain in the lower jaw improved. While on antihypertensive treatment patient was normotensive. The patient was discharged from the hospital in a good general condition with recommendations to continue treatment with corticosteroids. After 6 months of treatment prednisolone dose was reduced and was changed to T. Medrol $16 \mathrm{mg}$ x 1. Patient's serum creatinine $105 \mathrm{mcmol} / \mathrm{l}$ (GFR MDRD $75 \mathrm{ml} / \mathrm{min}$ ) and serum calcium $2.6 \mathrm{mmol} / \mathrm{L}$.

\section{Discussion}

Sarcoidosis is a multisystem disease of unknown etiology which mostly affect mediastinum and lungs [4]. Renal involvement is rare but can be severe and progress to the end stage renal disease [5]. There are several cases in the medical literature about renal insufficiency in sarcoidosis. The most common histological entity in the series of Löffler $U$ et al. which included 27 cases was non-granulomatous tubulointerstitial nephritis (44\%), then granulomatous interstitial nephritis (30\%), IgA nephropathy (26\%) and nephrocalcinosis (11\%). The first line treatment of sarcoidosis is corticosteroids. The prognosis of sarcoidosis is good, can occur spontaneous remission as well [4].

\section{References}

1. Bergner R, Hoffmann M, Waldherr R, Uppenkamp M (2012) Frequency of kidney disease in chronic sarcoidosis. Sarcoidosis Vasc Diffuse Lung Dis. 20: 126-32.

2. Hilderson I, Laecke S, Wauters A, Donck J (2014) Treatment of renal sarcoidosis: is there a guideline? Overview of the different treatment options. Nephrol Dial Transplant 29: 1841-1847.

3. Nunes H, Bouvry D, Soler P, Valeyre D (2007) Sarcoidosis. Orphanet J Rare Dis 2:46

4. Löffler U, Tuleweit A, Waldherr R, Uppenkamp M, Bergner R (2015) Renal Sarcoidosis epidemiological and follow-up data in a cohort of 27 patients. Sarcoidosis Vasc Diffuse Lung Dis 31:306-315.

5. Manjunath V, Moeckel G, Dahl NK (2013) Acute kidney injury in a patient with sarcoidosis: hypercalciuria and hypercalcemia leading to calcium phosphate deposition. Clin Nephrol. 80: 151-155.

Copyright: (C2017 Meshechko V. This is an open-access article distributed under the terms of the Creative Commons Attribution License, which permits unrestricted use, distribution, and reproduction in any medium, provided the original author and source are credited. 